\title{
TINGKAT KESEJAHTERAAN PENGRAJIN ANYAMAN MENSIANG DI JORONG TARATAK NAGARI KUBANG KECAMATAN GUGUAK KABUPATEN 50 KOTA
}

\author{
Elin setia gusni ${ }^{1}$, Afdhal ${ }^{2}$, \\ Program Studi Pendidikan Geografi, \\ Fakultas Ilmu Sosial, Universitas Negeri Padang \\ Email: elinsetiagusni01@gimail.com
}

\begin{abstract}
Abstrak
Anyaman mensiang merupakan pekerjaan yang turun-temurun dari nenek moyang masyarakat Jorong Taratak sampai sekarang ini. Penelitian ini bertujuan untuk mengetahui tingkat kesejahteraan pengrajin anyaman mensiang di Jorong Taratak Nagari Guguak Kabupaten 50 Kota. Jenis penelitian menggunakan metode deskriptif pendekatan kuantitatif. Teknik pengambilan sampel menggunakan Total Sampling dengan jumlah sampel 61 orang. Alat pengumpulan data adalah angket dan data diolah dengan menggunakan formula persentase dan menggunakan alat ukur skala likert (Sugiyono, 2003:86). Hasil penelitian: 1) tingkat kesejahteraan pengrajin anyaman mensiang di Jorong Taratak Nagari Kubang Kecematan Guguak Kabupaten 50 Kota tergolong tidak sejahtera, $39(63,93 \%)$ responden yang termasuk dalam kesejahteraan rendah, 20 $(32,79 \%)$ responden yang termasuk dalam kesejahteraan sedang dan $2(3,28 \%)$ responden yang termasuk kategori kesejahteraan tinggi. 2) faktor penentu tingkat kesejahteraan pengrajin anyaman mensiang adalah (a) kependudukan (b) kesehatan dan gizi (c) pendidikan (d) ketenagakerjaan (e) taraf dan pola konsumsi (f) perumahan dan lingkungan (g) kemiskinan (h) indikator sosial lain. Dalam penentuan tingkat kesejahteraan dari beberapa faktor penentu diatas dengan menggunakan skala likert, tidak ada yang termasuk kategori kesejahteraan tinggi.
\end{abstract}

Kata kunci : Kesejahteraan, Pengrajin

\section{Abstract}

This study aims to determine the level of well-being of woven craftsmen in Jorong Taratak Nagari Guguak Kabupaten 50 Kota. This type of research uses the descripyive method of the quantitative approach. The sampling technique uses total sampling whit a sample of 61 people. Data collection tools are questionnaires and data is processed using a percentage formula and uses a likert scale measuring instrument (Sugiyono 2003:86). Research result 1) the level of the woven craftsmen is in Jorong Taratak Nagari Guguak Kabupaten 50 Kota is classified as not prosperous, 39 (63,93\%) respondents included in low welfare, 20 (32,79\%) respondents included in moderate welfare, and $2(3,28 \%)$ respondents who included high welfare. 2$)$ the determinants of the level of welfare of the aging woven craftsmen are (a) population $(b)$ health and nutrition $(c)$ education $(d)$ employment (e)level and pattern of consumption $(f)$ housing and environment $(g)$ proverti (h) other social indicators. In the determinants of welfare levels of several of the determinants above using the likert scale, none of which belong to the high welfare category.

Keywords: welfare, craftsmen

\footnotetext{
${ }^{1}$ Mahasiswa Program Studi Pendidikan Geografi

${ }^{2}$ Dosen Jurusan Geografi Fakultas Ilmu Sosial Universitas Negeri Padang Drs. Afdhal, M.Pd
} 


\section{Pendahuluan}

Ekonomi kreatif diakui memiliki peran yang sangat strategis dalam pembangunan strategis dalam pembangunan ekonomi dan pembangunan bisnis. Dalam lima tahun terakhir ini istilah ekonomi kreatif atau industri kreatif marak dibicarakan. Terlebih ketika mantan presiden Susilo Bambang Yudhoyono menyebutkan tentang pentingnya pengembangan ekonomi kreatif baik masa depan ekonomi Indonesia. Implementasi konsep ekonomi kreatif ke bentuk pengembangan industri kreatif adalah solusi cerdas dalam mempertahankan keberlanjutan pembangunan ekonomi dan pengembangan bisnis di era global. (Moelyono:2010).

Keterampilan

yang

dibutuhkan dalam suatu industri kecil adalah keterampilan yang menyangkut proses pengerjaan, pengelolaan serta pemasaran. Idustri kecil pada umumnya memerlukan tenaga kerja kasar, dalam arti tenaga kerja yang langsung terlibat dalam proses produksi. Dengan begitu, keterampilan seorang tenaga kerja sangat besar peranannya terhadap industri kecil. Keterampilan ini umumnya didapatkan tenaga kerja dari kebiasaan dalam bekerja, pelatihan-pelatihan maupun keinginan dari tenaga kerja itu sendiri untuk lebih meningkatkan keterampilan dan pendapatannya.

Industri kerajinan anyaman mensiang memiliki prospek masa depan yang baik karena potensi alam yang melimpah dan mempunyai tujuan untuk membangun kemandirian masyarakat. Dibukanya kesempatan kerja baru tersebut diharapkan terciptanya usaha industrialisasi di suatu daerah. Dari berbagai industri kecil atau kerajinan yang ada, sebelumnya peneliti telah melekukan pengamatan dan mendapatkan informasi mengenai anyaman mensiang yang terbuat dari rerumputan mensiang yang dikanyam menjadi barang yang bermamfaat. Anyaman mensiang dapat dijadikan sebagai barang kerajinan yang memiliki nilai ekonomi yang lebih tinggi. (dalam Bakri, 2011)

Dengan memamfaatkan
tumbuhan liar yang telah
dibudidayakan yang disebut
mensiang, Dari bahan ini dibuat
aneka produk anyaman yang dapat
dimamfaatkan untuk keperluan
sehari-hari. Berbagai barang kerajinan yang unik dan kreatif dapat dihasilkan dari tanaman mensiang. Kreasi dari hasil tanaman mensiang yang dikanyam menjadi sebuah kerajinan yang dipergunakan untuk keperluan sehari-hari berbagai bentuk seperti (kombuik), tas, dompet, aksesoris kunci, tikar dan barang kerajinan lainnya. (dalam Bakri, 2011)

Kerajinan adalah kegitan yang kreatif yang berkaitan dengan kreasi, produksi, dan distribusi produk yang dibuat oleh pengrajin dari berbagai jenis bahan. Produk biasanya dalam jumlah terbatas dan bukan produksi masal.

Tingkat kesejahteraan suatu rumah tangga salah satunya dapat dilihat dengan jelas melalui besarnya pendapatan yang diterima untuk rumah tangga yang bersangkutan (BPS, 1998). 
Papan (Perumahan) Menurut Yusmar (2012) "Perumahan adalah suatu tempat tinggal dimana keluarga hidup teratur, sehingga pertumbuhan jasmani, rohani, sosial terjalin dengan baik sehingga memungkinkan untuk mempertebal atau memelihara rasa kekeluargaan.

\section{Metode Penelitian}

Jenis penelitian ini termasuk jenis penelitian deskriptif dengan pendekatan kuantitatif yaitu penelitian yang bertujuan untuk menjelaskan, meringkas kondisi dalam berbagai situasi, atau berbagai variabel yang timbul di masyarakat berdasarkan apa adanya sesuai dengan yang terjadi.

Populasi penelitian ini seluruh pengrajin anyaman mensiang yang merupakan pencharian pokoknya sebagai pengrajin anyaman mensiang.responden diperoleh menggunakan teknik total sampling yang berjumlah sebanyak 61 responden..

Teknik pengumpulan data menggunakan angket dan analisis data dengan menggunakan formula persentase dengan rumus:

$$
P=\frac{f}{n} \times 100 \%
$$

Sumber : (sudjana, 2007).

Keterangan:

$$
\begin{aligned}
& \mathrm{P}=\text { Persentase } \\
& \mathrm{f}=\text { Frekuensi }
\end{aligned}
$$

\section{Hasil Penelitian Dan Pembahasan}

$$
\begin{gathered}
\mathrm{n}=\text { Jumlah Responden } \\
\text { Dalam penelitian ini }
\end{gathered}
$$
menggunakan alat akur skala liker, proses pengolahan data dilakukan untuk menentukan skala atau bobot dari jawaban-jawaban kuesioner tersebut (Sugiyono, 2003:86). Dapat ditentukan bobot penelitian dengan menggunakan tingkat kesejahteraan masyarakat pengrajin anyaman mensiang dilihat dari delapan indikator yaitu kependudukan, kesehatan dan gizi, pendidikan, kemiskinan, dan indikator sosial lainnya yang dapat dihitung melalui nilai

$$
\mathrm{Ns}=\frac{(\mathrm{A} \times 3)+(\mathrm{B} \times 2)+(\mathrm{C} \times 1)}{\mathrm{N}}
$$

$\mathrm{A}=$ mampu dengan bobot 3

$\mathrm{B}=$ cukup dengan bobot 2

$\mathrm{C}=$ tidak mampu dengan bobo 1

$\mathrm{N}=$ jumlah responden

$\mathrm{Ns}=$ nilai skor

1. Ns 1-2,5 : Kategori rendah

2. Ns 2,6- 2,9 : Kategori Sedang

3. Ns $\geq 3$ : Kategori tinggi

Penelitian ini menggunakan metode deskripif kuantitatif, responden diperoleh menggunakan teknik total sampling yang berjumlah sebangak 61 responden. maka peneliti mengambil semua pengrajin anyaman mensiang di Jorong Taratak Nagari Kubang Kecamatan Guguak Kabupaten

50

Kota. tingkat kesejahteraan pengrajin 
anyaman mensiang di Jorong Taratak Nagari Kubang Kecamatan Guguak Kabupaten 50 Kota. Dari 8 faktor penentu yaitu: kependudukan, kesehatan dan gizi, pendidikan,

Tabel 1 : Kategori Tingkat

KesejahteraanPengrajin Anyaman

Mensiang Di Jorong Taratak Nagari Kubang Kecamatan Guguak

\begin{tabular}{lcc}
\hline Kriteria & F & $\%$ \\
\hline Rendah & 39 & 63,93 \\
\hline Sedang & 20 & 32,79 \\
\hline Tinggi & 2 & 32,79 \\
\hline Total & 61 & 100 \\
\hline
\end{tabular}

Berdasarkan tabel 1, dapat diketahui bahwa frekuensi pengrajin kerajinan anyaman mensiang yang termasuk dalam tingkat kesejahteraan rendah sebanyak 39 orang $(63,93 \%)$. Sementara itu ketenagakerjaan, taraf dan pola konsumsi, perumahan dan lingkungan, kemiskinan, dan kebutuhan sosial lainnya. (BPS, 2011) frekuensi atau jumlah pengrajin dengan tingkat kesejahteraan sedang sebanyak 20 orang $(32,79 \%)$. Dan 2 orang $(32,79)$ yang termasuk tingkatkesejahteraan tinggi.

Dari delapan indikator yaitu :

a. Kependudukan

Tabel 2 : Kesejahteraan Berdasarkan Indikator Kependudukan

\begin{tabular}{|c|c|c|c|c|c|c|c|c|c|}
\hline \multirow{2}{*}{ Pernyataan } & \multicolumn{2}{|c|}{ Tinggi } & \multicolumn{2}{|c|}{ Sedang } & \multicolumn{2}{|c|}{ Rendah } & \multirow{2}{*}{$\begin{array}{c}\text { Resp } \\
\text { onden }\end{array}$} & \multirow{2}{*}{ Skor } & \multirow{2}{*}{$\begin{array}{l}\text { Kate } \\
\text { Gori }\end{array}$} \\
\hline & $\mathrm{F}$ & $\%$ & $\mathrm{~F}$ & $\%$ & $\mathrm{~F}$ & $\%$ & & & \\
\hline Kependudukan & 45 & 73,77 & 11 & 18,03 & 5 & 8,19 & 61 & 2,7 & $\mathrm{~S}$ \\
\hline Jumlah & 45 & & 11 & & 5 & & & 2,7 & \\
\hline Rata-rata & & 73,77 & & 18,03 & & 8,19 & & 2,7 & $\mathrm{~S}$ \\
\hline
\end{tabular}

Sumber: Pengolahan Data Primer 2019

Dari tabel 2 berdasarkan rekapitulasi pengrajin anyaman mensiang pengukuran skala likert kategori usia pengrajin anyaman mensiang memiliki rata-rata skor 2,7 adalah memiliki frekuensi $73,77 \%$ berada pada kategori tinggi (usia produktif). sedang. Dan kategori mayoritas usia

b. Kesehatan dan gizi

Tabel 3: Kesejahteraan Berdasarkan Indikator Kesehatan Dan Gizi

\begin{tabular}{|c|c|c|c|c|c|c|c|c|c|}
\hline \multirow{2}{*}{ Pernyataan } & \multicolumn{2}{|c|}{ Tinggi } & \multicolumn{2}{|c|}{ Sedang } & \multicolumn{2}{|c|}{ Rendah } & \multirow{2}{*}{$\begin{array}{l}\text { Resp } \\
\text { onden }\end{array}$} & \multirow{2}{*}{ Skor } & \multirow{2}{*}{$\begin{array}{l}\text { Kate } \\
\text { gori }\end{array}$} \\
\hline & $\mathrm{F}$ & $\%$ & $\mathrm{~F}$ & $\%$ & $\mathrm{~F}$ & $\%$ & & & \\
\hline Kondisi kesehatan & 48 & 78,69 & 12 & 19,67 & 1 & 1,64 & 61 & 2,8 & $\mathrm{~S}$ \\
\hline $\begin{array}{l}\text { Kondisi ketercukupan } \\
\text { asupan gizi }\end{array}$ & 32 & 52,46 & 22 & 36,07 & 7 & 11,48 & 61 & 2,41 & $\mathrm{R}$ \\
\hline Jumlah & 80 & & 34 & & 8 & & & 16,3 & \\
\hline
\end{tabular}




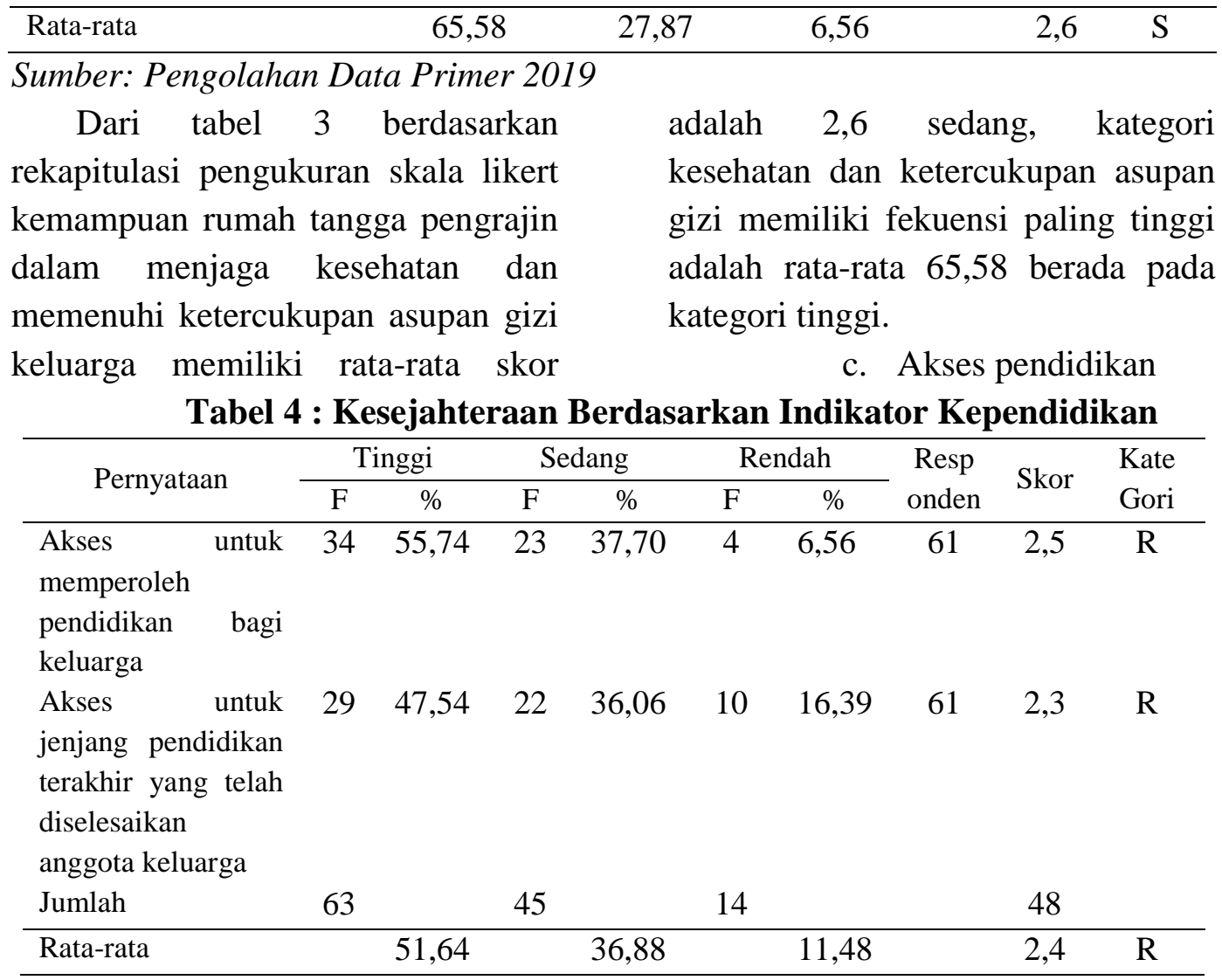

Sumber: Pengolahan Data Primer 2019

Dari tabel 4 berdasarkan memiliki fekuensi paling tinggi rekapitulasi pengukuran skala likert adalah rata-rata 51,64 berada pada kategori pendidikan keluarga kategori tinggi.

memiliki rata-rata skor adalah 2,4

rendah, kategori pendidikan

d. Ketenaga kerjaan

Tabel 5 : Kesejahteraan Berdasarkan Indikator Ketenagakerjaan

\begin{tabular}{|c|c|c|c|c|c|c|c|c|c|}
\hline \multirow{2}{*}{ Pernyataan } & \multicolumn{2}{|c|}{ Tinggi } & \multicolumn{2}{|c|}{ Sedang } & \multicolumn{2}{|c|}{ Rendah } & \multirow{2}{*}{$\begin{array}{l}\text { Resp } \\
\text { onden }\end{array}$} & \multirow{2}{*}{ Skor } & \multirow{2}{*}{$\begin{array}{l}\text { Kate } \\
\text { gori }\end{array}$} \\
\hline & $\mathrm{F}$ & $\%$ & $\mathrm{~F}$ & $\%$ & $\mathrm{~F}$ & $\%$ & & & \\
\hline $\begin{array}{l}\text { Status pekerjaan } \\
\text { berdasarkan waktu kerja }\end{array}$ & 42 & 68,85 & 18 & 29,51 & 1 & 1,64 & 61 & 2,7 & $\mathrm{~S}$ \\
\hline Jumlah & 42 & & 18 & & 1 & & & & \\
\hline Rata-rata & & 68,85 & & 29,51 & & 1,64 & & 2,7 & $S$ \\
\hline
\end{tabular}

Sumber: Pengolahan Data Primer 2019

Dari tabel 5 berdasarkan rekapitulasi pengukuran skala likert kategori status ketenagakerjaan memiliki rata-rata skor 2,7 adalah adalah rata-rata 68,85 berada pada kategori tinggi.
e. Taraf dan pola konsumsi

sedang, kategori ketenagakerjaan

memiliki fekuensi paling tinggi

Tabel 6: Taraf Dan Pola Konsumsi Rumah Tangga Pengrajin 


\begin{tabular}{|c|c|c|c|c|c|c|c|c|c|}
\hline \multirow{2}{*}{ Pernyataan } & \multicolumn{2}{|c|}{ Tinggi } & \multicolumn{2}{|c|}{ Sedang } & \multicolumn{2}{|c|}{ Rendah } & \multirow{2}{*}{$\begin{array}{l}\text { Resp } \\
\text { onden }\end{array}$} & \multirow{2}{*}{ Skor } & \multirow{2}{*}{$\begin{array}{l}\text { Kate } \\
\text { Gori }\end{array}$} \\
\hline & $\mathrm{F}$ & $\%$ & $\mathrm{~F}$ & $\%$ & $F$ & $\%$ & & & \\
\hline $\begin{array}{l}\text { Jumlah pendpatan dalam } \\
\text { satu bulan }\end{array}$ & 17 & 27,87 & 36 & 59,02 & 8 & 13,11 & 61 & 2,1 & $\mathrm{R}$ \\
\hline $\begin{array}{l}\text { Pengeluaran kebutuhan } \\
\text { untuk konsumsi dibanding } \\
\text { dengan kebutuhan lain non- } \\
\text { konsumsi }\end{array}$ & 20 & 32,79 & 38 & 62,3 & 3 & 4,92 & 61 & 2,3 & $\mathrm{R}$ \\
\hline $\begin{array}{l}\text { Pengeluaran untuk } \\
\text { konsumsi dalam satu bulan }\end{array}$ & 22 & 36,07 & 31 & 50,82 & 8 & 13,11 & 61 & 2,2 & $\mathrm{R}$ \\
\hline Jumlah & 59 & & 105 & & 19 & & & 6,6 & \\
\hline Rata-rata & & 32,24 & & 57,38 & & 10,38 & & 2,2 & $\mathrm{R}$ \\
\hline
\end{tabular}

Sumber: Pengolahan Data Primer 2019

Dari tabel 6 berdasarkan rekapitulasi pengukuran skala likert kategori status taraf dan pola konsumsi memiliki rata-rata skor adalah 2,2 kategori rendah, kategori taraf dan pola konsumsi memiliki

fekuensi paling tinggi adalah ratarata 57,38 berada pada kategori sedang.

\section{Tabel 7 : Kesejahteraan Berdasarkan Indikator Perumahan Dan}

\section{Lingkungan}

\begin{tabular}{|c|c|c|c|c|c|c|c|c|c|}
\hline \multirow{2}{*}{ Pernyataan } & \multicolumn{2}{|c|}{ Tinggi } & \multicolumn{2}{|c|}{ Sedang } & \multicolumn{2}{|c|}{ Rendah } & \multirow{2}{*}{$\begin{array}{l}\text { Resp } \\
\text { onden }\end{array}$} & \multirow{2}{*}{ Skor } & \multirow{2}{*}{$\begin{array}{l}\text { Kate } \\
\text { Gori }\end{array}$} \\
\hline & $\mathrm{F}$ & $\%$ & $\mathrm{~F}$ & $\%$ & $\mathrm{~F}$ & $\%$ & & & \\
\hline $\begin{array}{l}\text { Kemampuan Keluarga } \\
\text { Untuk Jenis Rumah } \\
\text { yang Ditempati }\end{array}$ & 46 & 75,41 & 15 & 24,59 & 0 & 0 & 61 & 2,8 & $\mathrm{~S}$ \\
\hline $\begin{array}{l}\text { Kemampuan Keluarga } \\
\text { Untuk Status Pemilikan } \\
\text { Rumah yang Ditempati }\end{array}$ & 31 & 50,82 & 29 & 47,54 & 1 & 1,64 & 61 & 2,5 & $\mathrm{R}$ \\
\hline Jumlah & 77 & & 44 & & 1 & & & 5,3 & \\
\hline Rata-rata & & 63,12 & & 36,07 & & 0,82 & & 2,7 & $\mathrm{~S}$ \\
\hline
\end{tabular}

Sumber: Pengolahan Data Primer 2019

Berdasarkan tabel 7 rekapitulasi pengukuran skala likert kategori perumahan dan lingkungan memiliki rata-rata skor adalah 2,7 kategori lingkungan memiliki fekuensi paling tinggi adalah rata-rata 63,12 berada pada kategori tinggi.

g. Kemiskinan sedang,, kategori perumahan dan

Tabel 8 : Kesejahteraan Berdasarkan Indikator Kemiskinan

\begin{tabular}{|c|c|c|c|c|c|c|c|c|c|}
\hline \multirow{2}{*}{ Pernyataan } & \multicolumn{2}{|c|}{ Tinggi } & \multicolumn{2}{|c|}{ Sedang } & \multicolumn{2}{|c|}{ Rendah } & \multirow{2}{*}{$\begin{array}{l}\text { Resp } \\
\text { Onden }\end{array}$} & \multirow{2}{*}{ Skor } & \multirow{2}{*}{$\begin{array}{l}\text { Kate } \\
\text { Gori }\end{array}$} \\
\hline & $\mathrm{F}$ & $\%$ & $\mathrm{~F}$ & $\%$ & $\mathrm{~F}$ & $\%$ & & & \\
\hline $\begin{array}{l}\text { Kategori keluarga } \\
\text { terkait dengan tingkat } \\
\text { kemiskinan }\end{array}$ & 2,5 & 40,98 & 32 & 52,46 & 4 & 6,56 & 61 & 2,3 & $\mathrm{R}$ \\
\hline
\end{tabular}




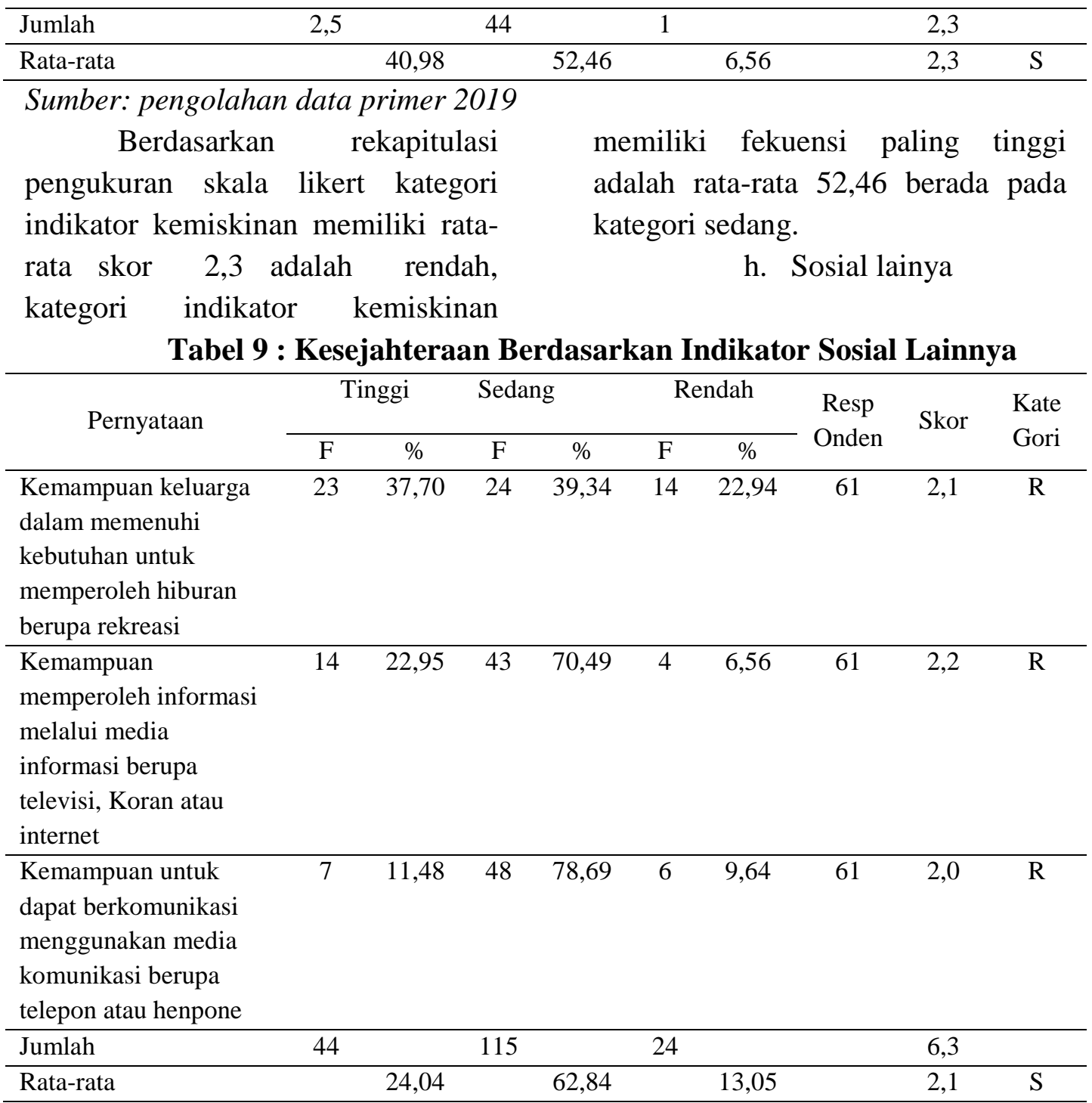

Sumber: pengolahan data primer 2019

Dari tabel diatas berdasarkan rekapitulasi pengukuran skala likert memiliki skor 2,1 adalah rendah, dan

\section{PENUTUP}

\section{Kesimpulan}

Berdasarkan hasil penelitian dan pembahasan yang disajikan pada bab empat, kesimpulan dari penelitian ini adalah sebagai berikut:

1. Tingkat kesejahteraan pengrajin anyaman mensiang di Jorong Taratak Nagari Kubang memiliki frekuensi tertinggi $62,84 \%$ termasuk kategori sedang.

Kecamatan Guguak Kabupaten 50 Kota dibagi menjadi tiga kriteria, yaitu tinggi, sedang, rendah. Jumlah pengrajin anyaman mensiang yang termasuk dalam tingkat kesejahteraan rendah sebanyak 39 orang $(63,93 \%)$, sementara itu frekuensi atau jumlah pengrajin dengan tingkat kesejahteraan sedang sebanyak 
20 orang (32,79\%). Jumlah pengrajin yang tergolong dalam tingkat

kesejahteraan tinggi hanya 2 orang $(3,28)$. Sehingga dapat disimpulkan secara umum taraf hidup pengrajin anyaman mensiang di Jorong Taratak Nagari Kubang Kecamatan Guguak Kabupaten 50 Kota tergolong kesejahteraan rendah.

2. Faktor penentu kesejahteraan pengrajin anyaman mensiang di Jorong Taratak Nagari Kubang Kecamatan Guguak Kabupaten 50 Kota menurut data BPS indikator atau unsur-unsur yang menentukan tingkat kesejahteraan seseorang atau suatu keluarha adalah didasarkan pada delapan indikator, yaitu:

a.Kependudukan

Kategori usia dalam rumah tangga pengrajin anyaman mensiang mayoritas rumah tangga tergolong dalam usia produktif yang memiliki frekuensi 73,77\% (usia 15-64 tahun)

b. Kesehatan dan gizi

Kemampuan rumah tangga pengrajin anyaman mensiang dalam menjaga kesehatan dan memenuhi ketercukupan asupan gizi mayoritas rumah tangga pengrajin termasuk dalam kategori tinggi dengan frekuensi 65,58\%.

c. Pendidikan
Kemampuan rumah tangga pengrajin untuk memperoleh akses pendidikan dan kemampuan untuk memperoleh akses jenjang pendidikan terahir yang telah diselesaikan anggota keluarga, termasuk dalam kategori tinggi dengan frekuensi 51,64\%.

d. Ketenaga kerjaan

Kemampuan rumah tangga pengrajin berdasarkan waktu kerjanya, diatas 35 jam/minggu dengan frekuensi $66,85 \%$ termasuk dalam kategori tinggi

e. Taraf dan pola konsumsi

Rumah tangga pengrajin anyaman mensiang termasuk dalam kategori sedang dengan frekuensi 57,38\%.

f. Perumahan dan lingkungan

Kemampuan rumah tangga pengrajin anyaman mensiang terhadap rumah yang ditempati dan memjaga kondisi lingkungan termasuk dalam kategori tinggi dengan frekuensi 63,12\%.

g. Kemiskinan

Kategori rumah tangga pengrajin anyaman mensiang termasuk dalam kategori sedang dengan frekuensi $52,46 \%$.

h. Indikator sosial lainnya.

Kemampuan rumah tangga pengrajin anyaman mensiang untuk memenuhi kebutuhan sosial lainnya termasuk 
kategori sedang dengan frekuensi $62,48 \%$.

\section{Saran}

1. Bagi pengrajin anyaman mensiang di Jorong Taratak Nagari Kubang Kecamatan Guguak Kabupaten 50 Kota harus lebih meningkatkan produksi kerajinan anyaman ini dari sebelumnya dan masalah pemasaran dapat terus dikembangkan baik kemasyarakat lokal maupun regional.

2. Bagi pemerintah khususnya di Jorong Taratak Nagari Kubang Kecamatan Guguak Kabupaten 50 Kota hendaknya lebih memperhatikan usaha kerajinan anyaman mensiang yang ada.

3. Untuk permasalahan modal yang dialami oleh pengrajin hendaknya dicarikan jalan keluarnya oleh paguyuban, karena pada dasarnya keberadaan paguyuban tersebut berfungsi untuk menghindari kesenjangan penghasilan yang terlalu mencolok, yang berdampakpada perbedaan penghasilan yang mencolok.

4. Bagi peneliti selanjutnya, penelitian ini bisa dijadikan bahan rujukan dan pedoman yang bermamfaat dan menambah wawasan pembaca dan peneliti sendiri.

\section{DAFTAR PUSTAKA}

Badan Pusat Statistik. 1998.

Indikator Kesejahteraan

Rumah Tangga 1998. Jakarta: BPS.

Badan Pusat Statistik. 2011. Indikator Kesejahteraan Rumah Tangga 2005. Jakarta: BPS

https://id.m.wikipedia.org/wiki/mensi ang(diakses tanggal 24 agustus 2018)

Herawati Merla, Lina.(2014). Pemberdayaan Ekonomi Masyarakat Melalui Kerajinan Tempurung Kelapa Studi Dusun Santan, Guwosari Pajangan Bantul. Skripsi.Universitas Islam Sunan Kalijaga Yogyakarta.Fakultas Dakwah dan Komunikasi. Yopi. 2013. Jagat Kerajinan Tangan . Jakarta: Bumi Aksara.

YusmarEmmyKatin 2012.IlmuKesejahteraanK eluarga.Padang. UNP 